\title{
VACCINIA GANGRENOSA AND AGAMMAGLOBULINAEMIA
}

\author{
BY \\ KRIS SOMERS \\ From The Hospital for Sick Children, Great Ormond Street, London
}

(RECEIVED FOR PUBLICATION DECEMBER 20, 1956)

Normally, primary vaccination against smallpox produces a vesicle on an inflamed base in four days, enlarging for a further five days with umbilication, and healing under a scab in about three weeks. Pyogenic infection of the primary lesion is the most common complication of vaccinia. Secondary vaccinal lesions may occur as the result of autoinoculation of adjacent or distant areas of skin. The lesions are scanty and their distribution asymmetrical with a minor constitutional reaction. When more numerous and symmetrically distributed, there is malaise and fever indicating a generalized vaccinia. Its incidence is estimated at about 1 in 25,000 vaccinations (Blank and Rake, 1955), and the lesions, appearing one or two weeks after vaccination, resolve with the primary 'take'. A serious type of generalized vaccinia occurs in the presence of pre-existing skin disease, particularly eczema, and is a variety of Kaposi's varicelliform eruption, better called eczema vaccinatum. The prognosis in this rare complication used to be very serious, but with modern treatment is not so.

Approximately 1.78 million persons of all ages, of whom 1.05 million were under the age of 1 year, were primarily vaccinated in England and Wales under the National Health Service, during the fiveyear period 1950-54 (Ministry of Health, Annual Reports of the Chief Medical Officer, 1950-54). Of these, the complication of generalized vaccinia was notified in $\mathbf{7 8}$ cases (four notified cases of generalized vaccinia after re-vaccination are for obvious reasons excluded), an incidence of 1 in 22.9 thousand primary vaccinations at all ages. Of the total number, six were cases with pre-existing eczema, i.e., eczema vaccinatum, of which two were fatal. Only two cases of generalized vaccinia, in the absence of pre-existing skin disease, died. The one, a girl, aged 4 months, was reported by Laurance, Cunliffe and Dudgeon (1952) as a case of vaccinia gangrenosa; the other was a female infant who died presumably from the same complication on the forty-third day after primary vaccination (Ministry of Health, Annual Report of the Chief Medical Officer, 1952). In all other cases, recovery was rapid and complete.

Rare instances of severe similar forms of generalized vaccinia have been reported from time to time. Hutchinson (1879) first described a fatal case of gangrene of skin following vaccination, and he applied the term 'vaccinia gangrenosa' to his case and to that of Stokes (1880). More recently a total of 13 cases of vaccinia gangrenosa have been reported: (Acland and Fisher (1893); Shortt's case (Shortt, 1933) later detailed by Dible and Gleave (1934); Bigler and Slotkowski (1951); the case reported by Laurance et al. (1952) and later by Hall, Cunliffe and Dudgeon (1953); Laurance et al. (1952) mention three other cases of which they had personal communications; Keidan, McCarthy and Haworth (1953); Kozinn, Sigel and Gorrie (1955) reported another and mentioned four other cases, one of which was ascribed to Barbero, Gray, McNair Scott and Kempe $(1954,1955)$.)

Of the total number, the only authentic case of recovery was that of Barbero et al. $(1954,1955)$. The other reported case of recovery, mentioned by Laurance et al. (1952) and quoted by Keidan et al. (1953), was assumed for some reason or other to have recovered from the vaccinal lesions. On closer examination, however, it seems probable that the patient's death was related to vaccinia gangrenosa (Dudgeon, 1956).

Keidan et al. (1953) first reported agammaglobulinaemia in a case of vaccinia gangrenosa. The patient, a girl, was vaccinated at the age of 8 weeks, and died seven weeks later, after being unsuccessfully treated with post-vaccinal serum and intramuscular injections of gamma globulin. The second case is mentioned by Kozinn et al. (1955) together with the third described by them in a 3-month-old male with extensive metastatic lesions, which was also fatal despite intramuscular injections of gamma 
globulin, intravenous infusions of post-vaccinal plasma, antibiotics and also A.C.T.H. and cortisone. The infant died approximately four weeks after primary vaccination.

The case reported here is the fourth case of vaccinia gangrenosa associated with agammaglobulinaemia.

\section{Case Report}

History. A boy born on August 5, 1955, was admitted on February 13, 1956, aged 6 months, having been referred to The Hospital for Sick Children because of persistent unhealed primary and disseminated vaccinal lesions.

He was the third child of healthy parents. The pregnancy, birth and neonatal growth and development had been normal. The birth weight was $7 \mathrm{lb} .14 \mathrm{oz}$. $\mathrm{He}$ was breast-fed for two months and then changed to 'ostermilk' No. 2, on which he continued to thrive. There was no past history of infections or other illnesses. On direct questioning, however, the parents thought his skin had been somewhat dry since the age of 5 weeks, but there had been no obvious suggestion of infantile eczema.

Both parents and two sisters aged 9 and 7 years had been successfully and uneventfully vaccinated. The parents came from large healthy families. The mother's family was southern English, the father's family Irish. As far as it could be checked, there had been no family history of recurrent infections or deaths in infancy or childhood.

At the age of 12 weeks he was vaccinated on the right deltoid region at a local clinic. The scarification method was used. Two scratches were made, as lymph on the first scratch had been accidentally wiped off. Within a week two apparently normal 'takes' occurred, but the vesicle continued to extend and increase in size and discharged yellow pus. A week later he was seen at a local hospital and chlortetracycline ('aureomycin') ointment was prescribed in the belief that the vaccination had become secondarily infected.

Over the next few weeks, the vaccination sore had extended from the shoulder to the elbow and crops of small vesicles appeared on the forehead, behind the left ear and on the tongue. He went off his feeds, became irritable and developed a fever.

He was admitted to The Hospital for Sick Children 12 weeks after vaccination.

Examination. He was a small, ill-looking, fretful baby weighing $11 \frac{1}{2} \mathrm{lb}$., with a temperature of $101.6^{\circ} \mathrm{F}$. and pulse 180 /minute.

The striking findings were confined to the skin, which showed an eruption of flat plaques with well-defined bullous edges, circumferentially over the whole of the right arm, the left forehead and external ear, the right temple, tip of the nose and upper lip, and a large area of the perineum. Many of the lesions had shown progressive central necrosis resulting in sharply punchedout ulcers with a flat, bright red, granular base, at first covered by a yellowish-brown slough, firmly adherent.

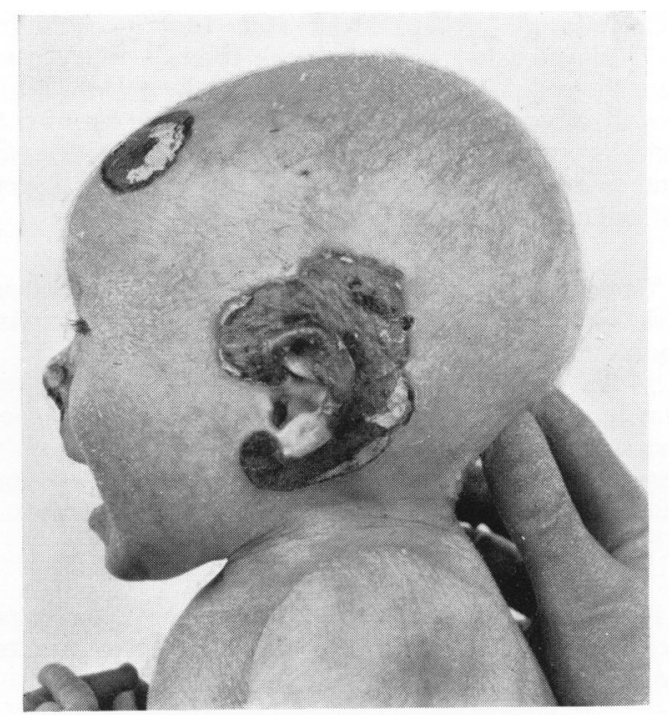

FIG. 1.

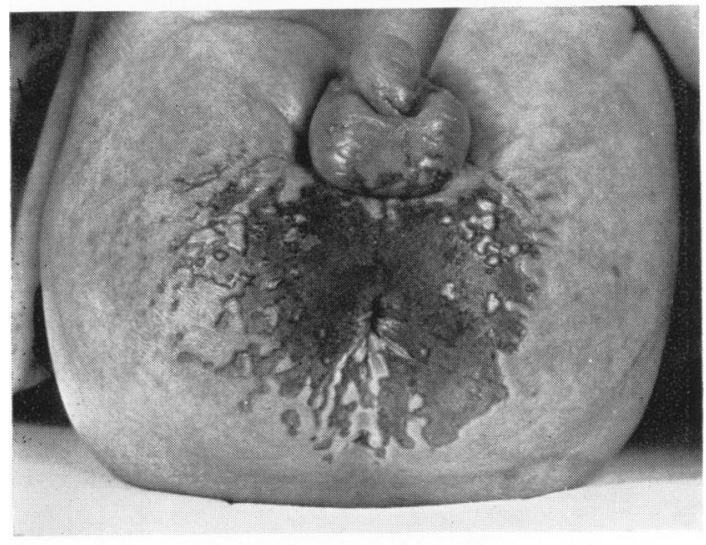

FIG. 2.

Figs. 1, 2.-Appearances 12 weeks after vaccination.

The margins of the necrotic areas were red for a few millimetres, but beyond this no inflammatory reaction was visible in the surrounding skin. There was drooling at the mouth and a circular ulcerated area on the dorsum of the tongue covered with mucopurulent exudate. The morphology of this shallow ulcer conformed closely with that of the skin lesions. The general dermatological picture was that of vaccinia gangrenosa (Figs. 1 and 2).

Examination of the chest was normal. The liver and spleen were palpable one fingerbreadth. No enlarged lymph nodes were evident.

Investigations. A blood count gave: Haemoglobin $58 \%$ (8.6 g./100 ml.); W.B.C. $11,800 /$ c.mm. (neutrophils $76 \%$, lymphocytes $16 \%$, monocytes $8 \%$ ); blood group, A $\mathrm{Rh}$ negative. 
Bacteriology. Swabs from skin lesions, including the perineum amd dorsum of the tongue, with Gram stain showed debris only. On culture there was a heavy growth of coagulase-positive staphylococci, sensitive to penicillin, streptomycin and chloramphenicol but resistant to tetracyclines and sulphonamides. Fungi were not isolated.

Virology. Dr. J. A. Dudgeon found that smears from vesicular lesions on the perineum showed a few elementary bodies, morphologically similar to vaccinia.

Swabs from the tongue and perineal lesions were heavily infected with coagulase-positive staphylococci and streptococci. Material had to be filtered owing to heavy secondary infection. The filtrate produced vaccinal-like lesions on the developing chick embryo.

Plasma proteins totalled $3.43 \mathrm{~g} . / 100 \mathrm{ml}$.

Electrophoresis. Classical Tiselius and filter paper techniques of electrophoresis failed to show gammaglobulin.

Treatment. After cleansing with normal saline, a lotion of $3 \%$ formalin in lot. calamine B.P. was applied to the skin and $3 \%$ formalin in glycerine to the tongue. The skin was later treated with 'neomycin' $1 \%$ ointment, to which the staphylococci were sensitive.

Chloramphenicol, $25 \mathrm{mg}$. six-hourly by mouth, was begun in preference to the tetracyclines, because of resistant skin staphylococci.

As soon as the presence of agammaglobulinaemia had been confirmed he was started on intramuscular injections of vaccinia gamma globulin, $250 \mathrm{mg}$. daily for nine days, totalling $2,250 \mathrm{mg}$. (22.5 ml.) supplied by the Public Health Laboratory, London.

Three hundred millilitres of compatible group A Rhnegative blood were transfused by a scalp vein and the haemoglobin was raised thereby to $96 \%(14 \cdot 2 \mathrm{~g} / / 100$ $\mathrm{ml}$.).

Progress. Although the skin lesions looked cleaner on treatment, the areas involved continued to extend. Fresh crops of flat-topped vesicles appeared ceaselessly. Swabs taken from them for virology were positive for vaccinia. No lesions developed at sites of venepuncture or intramuscular injection.

The temperature was unabated and after a week began to swing up to $105^{\circ} \mathrm{F}$. The baby looked ill and steadily deteriorated. His weight fell from $11 \frac{1}{2} \mathrm{lb}$. to less than $10 \mathrm{lb}$. A hoarse cry developed.

About the sixth day on chloramphenicol he began to pass continuous loose, watery stools. No pathogens were detected on examination. However, chloramphenicol was discontinued and injections of penicillin, 500,000 units, and streptomycin, $125 \mathrm{mg}$. b.d., to which the skin staphylococci were still sensitive, were begun. Tinct. opii. $\mathrm{m} \mathrm{1}$, eight-hourly did not improve the diarrhoea.

On the tenth day of admission he became jaundiced and drowsy. Liver function tests showed:

$$
\begin{aligned}
& \text { Serum bilirubin } \quad . . \quad \ldots 4.3 \mathrm{mg} . / 100 \mathrm{ml} \text {. } \\
& \text { Alkaline phosphatase } \ldots . \quad \ldots .13 \mu . / 100 \mathrm{ml} \text {. } \\
& \text { Thymol turbidity } \quad . \quad \quad \quad . \quad 1 \mu \mathrm{g} \text {. } \\
& \text { Zinc sulphate turbidity } \quad . \quad 1 \mu \mathrm{g} \text {. } \\
& \text { Blood urea } \quad . . \quad \ldots \quad \ldots 77 \mathrm{mg} . / 100 \mathrm{ml} \text {. }
\end{aligned}
$$

A repeat examination of plasma proteins after treatment with vaccinia gamma globulin showed:

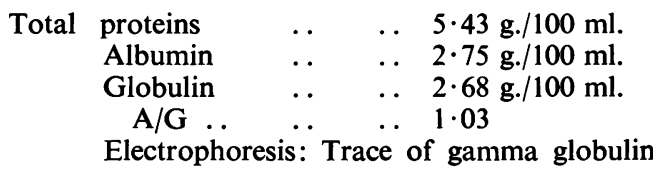

Two weeks after admission frank dry gangrene was seen over the right ear lobe. In the next few days he developed moist signs in the chest together with recession and died on the twentieth day of admission, approximately 15 weeks after primary vaccination.

Neutralization tests on serum collected at necropsy (Dr. J. A. Dudgeon) showed slight neutralizing activity to vaccinia virus but considerably less than that shown from a serum of a recently vaccinated person. It seemed probable that the small amount of neutralizing antibody was due to the residual gamma globulin which had been given to the child.

Necropsy Findings. The post-mortem examination was made by Dr. Martin Bodian. Inspection showed the wasted body of a male infant. Numerous well-defined ulcers with flat, reddened bases were noted over the scalp, external ears, tip of the nose, upper lip, right arm and perineum. There was a large, sharply defined ulcer on the dorsum of the tongue.

Both lower lobes of the lungs were consolidated and the other lobes showed small areas of consolidation, some with evidence of central suppuration. The mucosa of the trachea and bronchi was haemorrhagic and covered with a little granular purulent exudate.

The liver was moderately enlarged and the capsular and cut surfaces showed a mottled appearance, reddishbrown areas alternating with cream coloured areas. The lobular pattern was indistinct. The spleen was slightly enlarged, firm and plum coloured. Malpighian bodies were inconspicuous. The capsular and cut surfaces of the kidneys also showed a mottled appearance of alternating reddish-brown and cream coloured areas. The cortico-medullary pattern was well defined. The adrenals showed nothing abnormal.

A well-defined longitudinal ulcer with raised yellow margins was noted at the lower end of the oesophagus. There was considerable gaseous and fluid distension of the small bowel. The mucosa of the jejunum and ileum showed patchy hyperaemia but no ulceration.

The brain was oedematous. The myocardium was pale and flabby.

Gram stain of swabs from the right lower lobe and left bronchus showed polymorphonuclear cells and Grampositive cocci. Coagulase-positive staphylococci and Esch. coli were grown on culture. In addition the bronchial swab grew Streptococcus faecalis. 


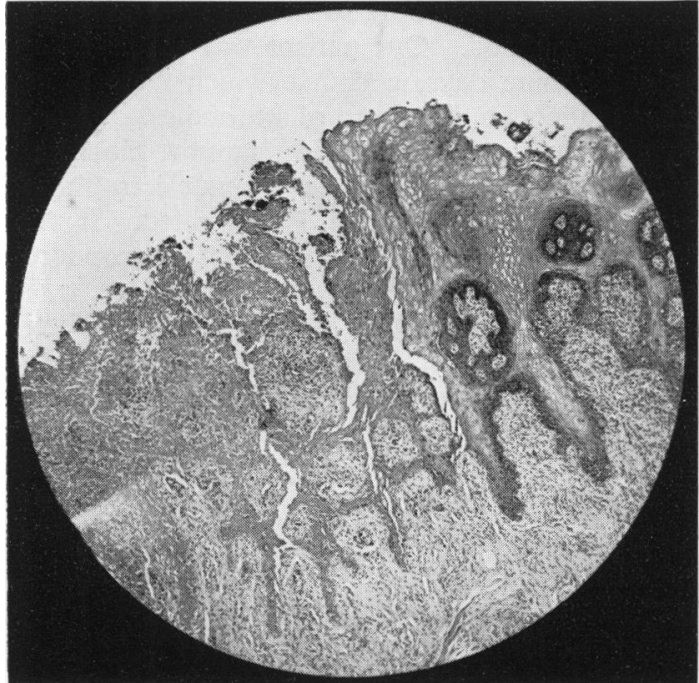

Fig. 3.-Photomicrograph of edge of ulcer of tongue, $\times 30$, showing necrosis of epithelium and scanty cellular response. Numerous 'ballooned' cells, in epithelium adjacent to ulcer. Clumps of cocci on surface of ulcer.

Histology. On section the tongue showed extensive mucosal ulceration and infiltration of the subjacent tissue with scanty mononuclear cells. Epithelial cells adjacent to the areas of necrosis showed considerable 'ballooning' and occasionally eosinophilic intracellular inclusion bodies (Fig. 3). A piece of skin from the arm showed hyperaemia and a little mononuclear infiltration of the epidermis as well as ballooning of some cells. Inclusion-containing cells were not seen. The perineal skin showed necrosis of the epidermis and hair follicles with scanty inflammatory cellular infiltration. Occasional epidermal cells contained eosinophilic inclusion bodies. Extensive focal necrosis of the mucosa and submucosa, including the muscularis mucosae and mucous glands, was shown on section of the lower oesophagus. A few adjacent epithelial cells contained eosinophilic inclusion bodies (Fig. 4).

The parenchymal cells of the liver revealed moderate vacuolation due to fatty change but in other respects the liver was normal. In particular there was no focal necrosis. The splenic pulp was congested. The malpighian lymphoid follicles were very inconspicuous and showed a most remarkable paucity of germinal centres. Sections of lymph nodes showed a similar marked reduction in follicles and absence of germinal centres. These changes were presumably associated with agammaglobulinaemia.

The kidneys showed small superficial subcapsular foci of mononuclear infiltration and there was generalized hyperaemia. There was nothing remarkable in the adrenals.

Sections of the lungs showed extensive necrotizing bronchitis and bronchiolitis with peribronchiolar extension of the inflammatory process. The bronchial mucosa

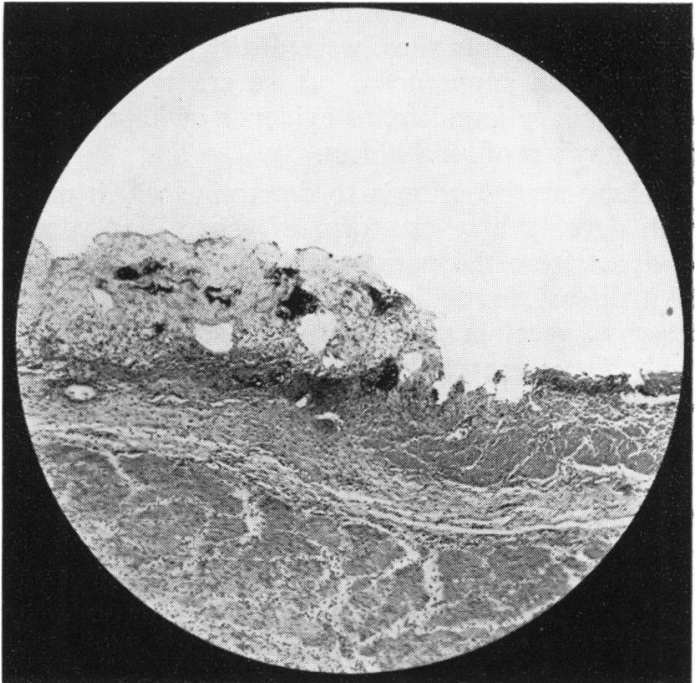

Fig. 4.-Photomicrograph of section of lower oesophagus, $\times 30$ showing edge of ulcer penetrating muscularis mucosae. Little inflammatory cellular response. Clumps of cocci in necrotic debris covering base of ulcer.

was almost completely shed. No inclusion-containing cells were seen (Fig. 5).

There was a slight excess of mononuclear cells in the leptomeninges and the epicardium. The brain and the heart were otherwise normal.

\section{Discussion}

The progressive necrotizing vaccinal reaction, failure to heal and the development of gangrene,

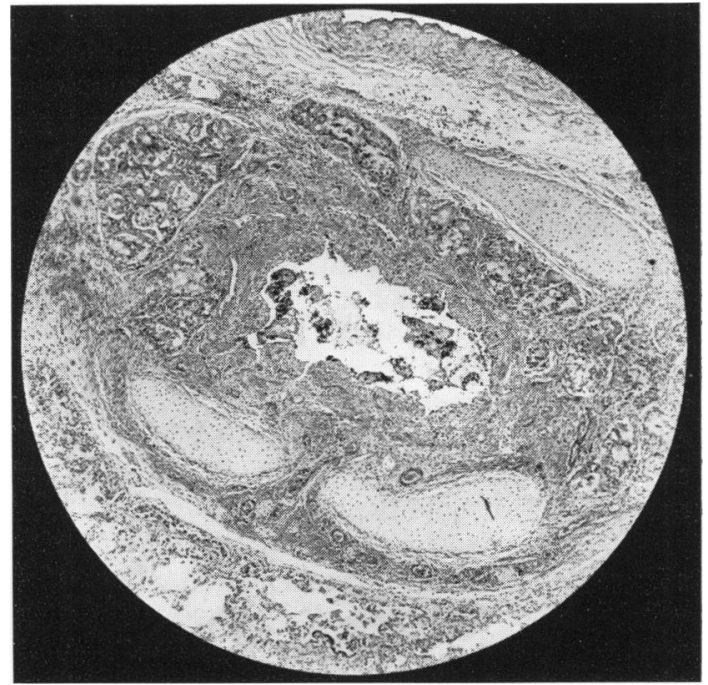

FIG. 5.-Photomicrograph of section of lung, $\times 30$, showing a branch bronchus. Necrosis of epithelium with poor cellular response; lumen filled with debris containing clumps of cocci. 
together with the continued appearance of fresh lesions at various sites, were distinguishing features of vaccinia gangrenosa. A severe toxaemia was suggested by jaundice, as evidence of hepatitis, and the baby's profound illness.

There are no criteria to determine which patient will develop a severe form of generalized vaccinia -apart from the patient with obvious pre-existing skin disease, particularly eczema. Of the 14 reported cases of vaccinia gangrenosa (including our patient) only five were checked for the blood content of gamma globulin. All four who lacked it died. Whilst agammaglobulinaemia has been increasingly noted in association with recurrent bacterial infections in childhood (leading article, British Medical Journal, 1955), it has been stated that patients with agammaglobulinaemia respond to vaccination without complication in contrast to their undue susceptibility to bacterial infections (Apt, 1953-54). However, the risk of severe vaccinal reaction and death, perhaps ascribable to secondary bacterial infection, is such that it would seem unwise to vaccinate patients with known agammaglobulinaemia, especially as the risk of smallpox is so small in western countries. It is advisable also to test for plasma gamma globulin in all patients with generalized vaccinal reactions.

All but one of the reported cases of primary agammaglobulinaemia have been boys, which points to an inherited sex-linked Mendelian trait. Should the parents of our patient have another male child, the chances of its having agammaglobulinaemia will be 1 in 4 . As for the exception, the case described by Keidan et al. (1953), it has been suggested that the deficient gamma globulin was not identical with that lacking in the boys (Hutchison, 1955). Agammaglobulinaemia in adolescents and adults of either sex seems to be the acquired variety (British Medical Journal, 1955).

Keidan et al. (1953) and also Kozinn et al. (1955) comment on the absence of enlarged lymph nodes together with a marked reduction of germinal centres in sections of lymph nodes in their cases. These observations have also been borne out in the present case, and in a number of reported cases of agammaglobulinaemia (leading article, British Medical Journal, 1955). The congenital inability to synthesize gamma globulin may perhaps be associated with atrophy of lymphoid tissue.

With regard to management, any patient with a generalized vaccinal reaction should be treated with vaccinia gamma globulin, which is now available in pure form for intramuscular injection. Immune plasma or blood from recently vaccinated donors is difficult to obtain and has proved disappointing in use. Larger amounts of vaccinia gamma globulin can be given as the pure substance than as immune plasma or blood. Our patient was given $250 \mathrm{mg}$. daily for nine days, a course which may be considered adequate in respect of antibodies. With the usual amounts administered, gamma globulin is unlikely to be reflected in the plasma electrophoretic pattern unless the serum is saturated. It may, however, be worth while doing serial electrophoretic examinations.

Because of concomitant secondary coccal infection and the destructive effect of staphylococcal necrotoxin, it is necessary to make full use of antibiotics. Broad spectrum oral antibiotics are preferable to injections of penicillin and streptomycin, provided the organisms are sensitive and the risk of sideeffects, particularly diarrhoea, is borne in mind. An adequate supplement of vitamin B complex and ascorbic acid should be given.

\section{Conclusion and Summary}

A case of a 6-month-old male infant with vaccinia gangrenosa is described. The local vaccinal reaction progressively enlarged and new lesions continually appeared. Plasma protein studies revealed agammaglobulinaemia. Virological studies confirmed the presence of vaccinia. There was secondary staphylococcal infection.

It would appear that the patient had no humoral defences against the virus, presumably because of the deficiency of gamma globulin and thus the subject was a perfect medium for the cultivation of vaccinia virus, which in consequence produced gross cutaneous and visceral damage. The patient was treated with intramuscular injections of vaccinia gamma globulin and various antibiotics without success. At necropsy the disease was characterized by lymphoid atrophy, absence of healing and poor inflammatory response.

Patients with agammaglobulinaemia should not be vaccinated and patients with generalized vaccinal reactions should be examined for gamma globulin.

I wish to thank Dr. S. Hall and Dr. A. P. Norman for permission to publish this report; Dr. Martin Bodian, Dr. R. T. Brain, Dr. J. A. Dudgeon and Professor N. H. Martin for much helpful advice; and Dr. F. O. MacCallum and Dr. J. C. MacDonald who supplied vaccinia gamma globulin.

I am particularly grateful to Dr. Norman for his encouragement in the preparation of this report, and Dr. Bodian for the findings at post-mortem examination.

Mr. Derek Martin, of the Photographic Department of The Hospital for Sick Children, kindly supplied the photographs.

\section{REFERENCES}

Acland, T. D. and Fisher, C. H. (1893). Trans. clin. Soc. Lond., 26, 114 Cited by Laurance et al. (1952).

Apt, L. (1953-54). Yearb. Pediat., p. 67. 
Barbero, G. J., Gray, A., Scott, T. F. McNair and Kempe, C. H. (1954). Amer. J. Dis. Child., 88, 395.

$7,-, \quad-$ (1955). Pediatrics, 16, 609.

Bigler, J. A. and Slotkowski, E. L. (1951). Ibid., 7, 24.

Blank, H. and Rake, G. (1955). Viral and Rickettsial Diseases of the Skin, Eye and Mucous Membranes of Man, p. 110. London.

Dible, J. H. and Gleave, H. H. (1934). J. Path. Bact., 38, 29.

Dudgeon, J. A. (1956). Personal Communication.

Hall, G. F. M., Cunliffe, A. C. and Dudgeon, J. A. (1953). J. Path. Bact., 66, 25.

Hutchinson, J. (1879). Brit. med. J., 2, 960.

Hutchison, J. H. (1955). Lancet, $2,844$.

Keidan, S. E., McCarthy, K. and Haworth, J. C. (1953). Archives of Disease in Childhood, $28,110$.
Kozinn, P. J., Sigel, M. M. and Gorrie, R, (1955). Pediatrics, 16, 600.

Laurance, B., Cunliffe, A. C. and Dudgeon, J. A. (1952). Archives of Disease in Childhood, $27,482$.

Leading Article (1955). Brit. med. J., 2, 32.

Ministry of Health (1950). Annual Report of the Chief Medical Officer. Pt. II, p. 22. Published 1952.

(1951). Ibid., Pt. III, p. 26. Published 1953.

(1952). Ibid., Pt. II, p. 32 . Published 1953.

(1953). Ibid., Pt. II, p. 31. Published 1954.

(1954). Ibid., Pt. II, p. 36 . Published 1955.

Shortt, C. J. de Vere (1933). Brit. med. J., 1, 1004.

Stokes, W. (1880). Dublin J. med. Sci., 69, 497. Cited by Laurance, et al. (1952). 